\title{
МЕТОДОЛОГИЧЕСКИЕ ОСНОВЫ ИССЛЕДОВАНИЯ ПОВЕДЕНИЯ ОБУЧАЮЩЕГОСЯ В ИНТЕРНЕТ-ПРОСТРАНСТВЕ ${ }^{1}$
}

\section{METHODOLOGICAL BASIS OF RESEARCH OF STUDENT BEHAVIOR IN THE INTERNET \\ V. Pisarenko}

Summary: The article discusses the system of methodological approaches to the study of the characteristics of student behavior in the Internet. The features of the informational stage of the development of society are analyzed. The hierarchical structure of the methodological foundations proposed by I.V. Blauberg and E.G. Yudin was used. Methodological approaches are analyzed at various levels.

Keywords: methodology, approach, information society, system.
Писаренко Вероника Игоревна

Д.п.н., профессор, Южный фредеральный университет

(2. Ростов-на-Дону) vero19671993@gmail.com

Аннотация: В статье рассматривается система методологических подходов к исследованию особенностей поведения обучающегося в Интернет-пространстве. Анализируются особенности информационного этапа развития общества. В качестве основы используется иерархическая структура методологических оснований, предложенная И.В. Блаубергом и Э.Г. Юдиным. Анализируются методологические подходы на различных уровнях.

Ключевые слова: методология, подход, информационное общество, система.
И зучение особенностей поведения обучающихся в Интернет-пространстве представляется актуальным в связи с тем, что Интернет-пространство сегодня во многом определяет формирование мировоззрения и стиля жизнедеятельности молодых людей, от которых зависит благополучие и будущее нашей страны. Отметим, что, по мнению многих ученых, современный этап развития общества определяется как информационный, поскольку именно информация играет ведущую роль в жизни человека, определяет, формирует и изменяет его мировоззрение, влияет на стиль жизни. Владение навыками взаимодействия с информационным полем определяет успешность человека в современном социуме [4].

Для информационного этапа развития общества характерны:

- рост социальной диверсификации жизни социума;

- высоким уровнем сложности принятия личностью решений о ее роли в системе всех существующих на сегодняшний день социальных отношений;

- высокой степенью неопределенности социальных установок;

- повышенной сложностью и постоянной динамикой системы ценностных установок личности как представителя определенной социальной группы как следствия быстрых изменений в экономическом, социальном, политическом, государственном устройстве страны;

- возрастанием гипермобильности населения и ростом социальной напряженности, обусловленными динамикой этнографической структуры общества, характеризующегося стремительными и сложнорегулируемыми миграционными процессами, приводящими к перемещению, дистанцированию и сближению конфессиональных, этнических, поколенческих и социальных слоев общества;

- появлением в социуме стереотипов восприятия проявлений этнофобии, жестокости, ксенофобии, мигрантофобии как привычных социальных норм и явным или скрытым копированием негативных образцов агрессивного поведения в деятельности отдельных личностей и социальных групп;

- широким распространением манипулятивных технологий формирования установок «свои-чужие», конструированием образа врага, использованием лингвистических и изобразительных средств, разжигающих вражду, в СМИ и сети Интернет;

- появлением у молодого поколения новых умений и навыков, связанных с поиском, восприятием, переработкой и актуализацией информации, что связано с более интенсивным взаимодействием с информационным полем, чем у предшествующих поколений.

Учет данных особенностей необходим для формирования более реальной картины взаимодействия личности и информационного поля, частью которого сегодня является Интернет-пространство.

Исследование выполнено при финансовой поддержке РФФИ в рамках научного проекта № 18-29-22019 мк 
В информационном обществе личность формируется, развивается и совершенствуется в условиях постоянно меняющегося информационного поля [5]. Данное понятие в наше время глобальной информатизации жизнедеятельности имеет различные ракурсы рассмотрения и определения в научной литературе.

Огромное количество времени, которое обучающиеся проводят в Интернет пространстве, не всегда связано с учебной деятельностью, с необходимостью поиска учебной информации. Интернет-пространство становится для молодых людей частью жизни, в которой многие из них проводят достаточно много времени. В связи С этим актуальность анализа поведения обучающихся в Интернет-пространстве не вызывает сомнений. Моделирование поведения обучающегося в Интернет-пространстве позволит рассмотреть и проанализировать все связанные с этим риски и опасности.

Моделирование поведения обучающегося необходимо осуществлять с использованием определенной методологии. Методологические проблемы современной науки продолжают оставаться на пике актуальности. Изучение явлений с позиций диалектики, т.е. науки о наиболее общих законах развития природы, общества и мышления, позволяет выявить их качественное своеобразие, связи с другими явлениями и процессами. Все они изучаются в их постоянном изменении и развитии, выявлении противоречий и путей их разрешения.

Методологию мы рассматриваем как учение не только о методах, но и об исходных положениях, принципах, способах познания, объяснительных схемах исследовательского поиска и практического преобразования действительности. Современный этап развития науки и, следовательно, ее методологии, определяется как постнеклассический, для которого характерны утверждение о сложности природных систем, цельности и неразрывности компонентов системы, условности выделения этих компонентов, понимание и признание крайней сложности исследуемых объектов.

Одной из концепций постнеклассического этапа развития науки является концепция методологического анализа научных явлений, предложенная И.В. Блаубергом и Э.Г. Юдиным [1, с. 68], разработанная на основе тезисов о типах и уровнях методологии, сформулированных впервые В.А. Лекторским и В.С. Швыревым [2]. Именно эту концепцию мы считаем необходимым использовать в формировании системы методологических подходов к анализу поведения обучающегося в Интернет-пространстве. Упомянутые и многие другие ученые считают методологию неотъемлемым элементом любого научного исследования [1, 2, 6, 7, 8, 9]. В соответствии с данной концепцией для исследования любого явления предлагается иерархическая структура методологиче- ских оснований, включающая следующие четыре уровня научного анализа:

- философский (мировоззренческий) - общая концепция мировоззрения, учение о роли и возможностях в преобразовании природы и общества, о целях и смыслах человеческой деятельности; содержание первого, высшего философского уровня методологии составляют общие принципы познания и категориальный строй науки в целом; методологические функции выполняет вся система философского знания;

- общенаучный - с общими для всех наук подходами и принципами, представляет собой теоретические концепции, применяемые ко всем или к большинству научных дисциплин;

- конкретно научный, вводящий в научную практику методологию той или иной науки, совокупность методов, принципов исследования и процедур, применяемых в той или иной специальной научной дисциплине; методология конкретной науки включает в себя как проблемы, специфические для научного познания в данной области, так и вопросы, выдвигаемые на более высоких уровнях методологии;

- собственно методический (технологический или дисциплинарный) уровень составляют методика и техника исследования, т.е. набор процедур, обеспечивающих получение достоверного эмпирического материала и его первичную обработку, после которой он может включаться в массив научного знания; на этом уровне методологическое знание носит четко выраженный нормативный характер.

Используя данную структуру методологических оснований и опираясь на исследования упомянутых выше ученых, мы предлагаем следующую систему методологических подходов, представленную на рис.1. На философском уровне, который представляет все основные принципы рассмотрения явлений действительности, взятые из философии, находятся наиболее общие для конкретного этапа развития научного познания принципы, которые обозначены в современной науке как принципы диалектического материализма: принцип единства теории и практики; творческий, конкретно-исторический подход к исследуемой проблеме; принцип объективности рассмотрения научных явлений; принцип всесторонности изучения процессов и явлений; комплексный подход к исследованию процессов и явлений; единство исторического и логического; системность. Важную методологическую роль играют категории диалектики - сущность и явление; причина и следствие; необходимость и случайность; возможность и действительность; содержание и форма; единичное, особенное и общее и др. Они являются надежным методологическим средством в руках исследователя-разработчика, дающим ему возможность глубоко и разносторонне решать сложные научно-тех- 


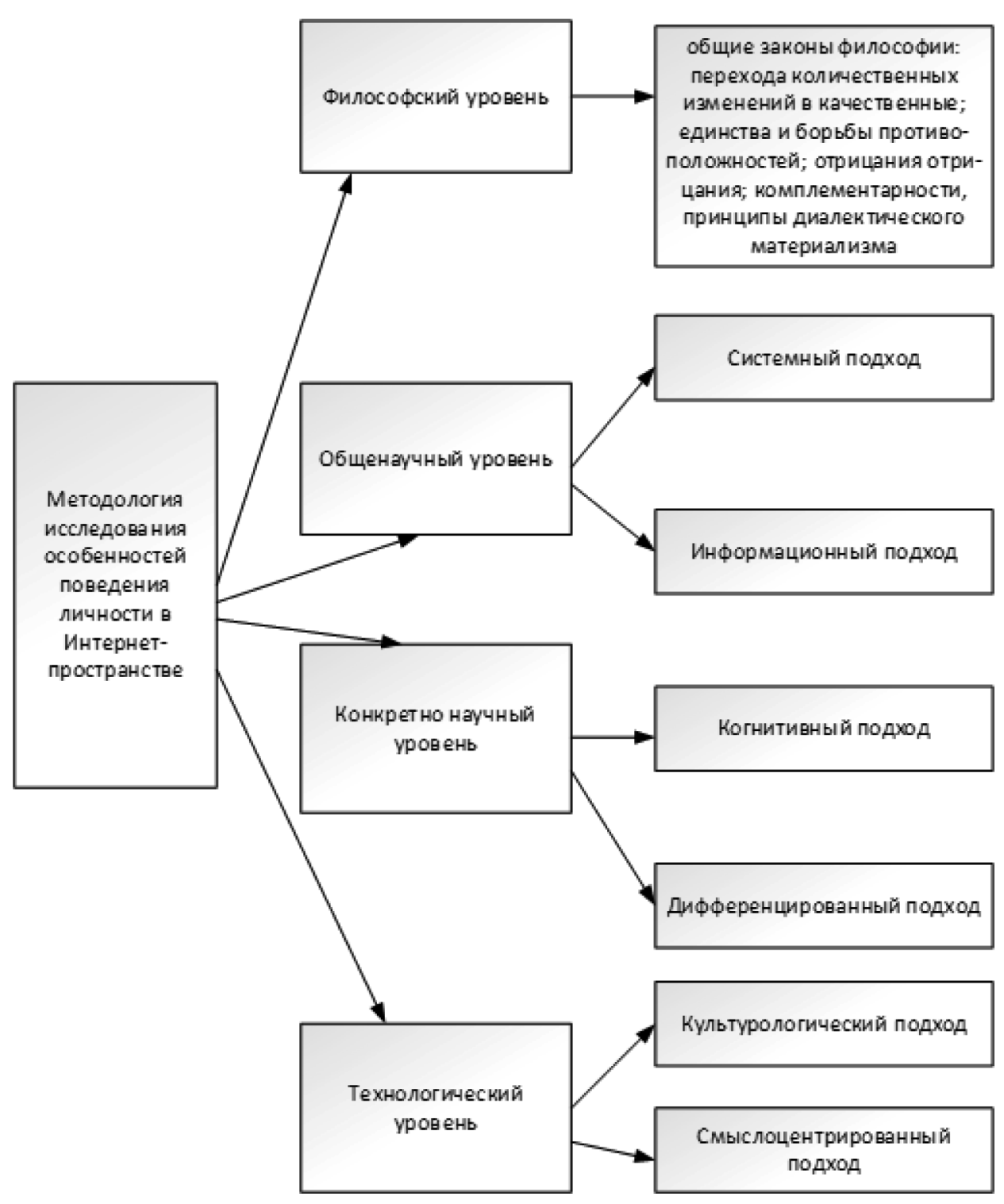

Рис. 1. - Структура методологических оснований исследования особенностей поведения личности в Интернет-пространстве

нические проблемы.

На базе накопленных фактов идет процесс поднятия эмпирического познания до уровня теоретического обобщения. Здесь характерно движение от одностороннего знания к все более разностороннему, выработка на основе первичных обобщений определенных моделей и идей, соединение чувственного и рационального, в ходе которого чувственные впечатления и практический опыт освобождаются от всего случайного и поднимаются до уровня теоретического, характерного для ряда подобных явлений. Разумеется, факты важно рассматривать в исторически конкретной обстановке, в целом, в их взаимосвязи, при этом условии они будут доказательны. К этому же уровню относятся законы философии: единства и борьбы противоположностей; отрицания отрицания; перехода количественных изменений в качественные; причинно-следственных связей; комплементарности.

На общенаучном уровне, который можно обозначить как уровень общенаучных принципов и форм исследования, мы используем системный и информационный подходы. Использование системного подхода означает рассмотрение деятельности обучающегося в Интернет-пространстве как системы действий или операций, определяемых поставленной целью деятельности. Системный подход позволяет рассмотреть деятельность как систему операций, связанных между собой. Кроме того, системный подход позволяет рассматривать личность обучающегося, взаимодействующего с информационным полем Интернет-пространства, как системное образование. Само Интернет-пространство рассматри- 
вается как информационная система, компоненты которой могут оказывать как положительное, так и отрицательное воздействие на личностную сферу. Мы также говорим о системе рисков при работе личности в сети Интернет. Информационный подход - метод научного познания объектов, процессов или явлений природы и общества, согласно которому в первую очередь выявляются и анализируются наиболее характерные информационные аспекты, определяющие функционирование и развитие изучаемых объектов. Основные понятия информационного подхода: информация (современный подход к ее определению), информационный процесс, информационная система, информационное моделирование, информационная сложность, информационное управление и др.

Информатика (теоретическая методологическая основа информационного подхода) осуществляет формализованный подход к объектам различной природы техническим, биологическим, социальным. Смысл этого подхода состоит в том, чтобы выделить в них стороны, связанные с переработкой информации, информационным управлением и др. [3].

На конкретно научном уровне, который содержит методы, принципы исследования и процедуры, применяемые в той или иной специальной научной дисциплине, мы предлагаем использовать когнитивный и дифференцированный подходы. Когнитивный подход представляет собой признание в качестве оснований рассматриваемого явления механизмов, компетенций, умений и навыков, которые использует человек при восприятии, обработке, осмыслении, хранении и актуализации информации в ходе взаимодействия с информационным полем. Речь идет также о способах организации знания, о развитии познавательных способностей. «Именно организация знаний, а не скорость переработки, предельно низкая с точки зрения технических систем, дает ключ к пониманию, по крайней мере, части наших познавательных способностей. Базовыми элементами концептуальной картины мира являются концепты - содержательные оперативные единицы знания. Именно этими единицами и структурами человек оперирует в процес- се мышления и речемыслительной деятельности. Основные понятия когнитивного подхода: знание/знания, когнитивный процесс, когнитивная система, когнитивное моделирование, когнитивный стиль, информационное управление и др.» [3, с.7].

Дифференцированный подход к исследованию поведения обучающегося в Интернет-пространстве означает учет и принятие во внимание индивидуальных личностных особенностей обучающихся. Мы все по-разному воспринимаем, обрабатываем и актуализируем одну и ту же информацию. Это обусловлено наличием различных ведущих каналов восприятия информации, различиями в скорости обработки информации и в способах ее запоминания. Это все связано с различными стилями познавательной деятельности, неодинаковой интенсивностью взаимодействия с информационным полем. То есть, личностные и индивидуальные особенности оказывают прямое воздействие на интенсивность информационного обмена личности и информационного поля.

На технологическом уровне мы выделяем в качестве основных культурологический и смыслочентрированный подходы. Культурологический подход означает, что деятельность обучающегося в Интернет-пространстве должна рассматриваться с позиций общей человеческой культуры, а само Интернет-пространство должно быть частью культурного пространства, что пока остается только целью в будущем. Кроме того, культурологический подход подразумевает формирование культуры информационной безопасности личности как части общей культуры. Смыслочентрированный подход позволяет нам объяснить с научной точки зрения те процессы, которые происходят в личностной сфере, когда новая информация сталкивается с личностными смыслами конкретной личности, происходит ее принятие или непринятие и далее осмысление на более глубоком уровне.

Таким образом, предлагаемая система методологических подходов к исследованию поведения обучающегося в Интернет-пространстве позволяет подойти к исследуемому явлению с позиций, соответствующих современной научной картине мира и в соответствии с современным типом научной рациональности.

\section{ЛИТЕРАТУРА}

1. Блауберг И.В., Юдин Э.Г. Становление и сущность системного подхода / И.В. Блауберг, Э.Г. Юдин. - М.: Изд-во «Наука», 1973. - 135 с.

2. Лекторский В.А., Швырев В.С. Методологический анализ науки (типы и уровни) // Философия. Методология. Наука / Отв. ред. В.А. Лекторский. М.: Наука, 1972. C. 7-44.

3. Миндзаева Э.В. Разработка концепции информационной безопасности личности: информационный/когнитивный подходы // Управление образованием: теория и практика. 2017. №2 (26). URL: https://cyberleninka.ru/article/n/razrabotka-kontseptsii-informatsionnoy-bezopasnosti-lichnosti-informatsionnyykognitivnyy-podhody (дата обращения: 17.08.2021)

4. Писаренко В.И. Методология инновационного образования в контексте динамики общенаучной картины мира // Известия ЮФу. Педагогические науки. № 5, 2008.c. 13-21. 
5. Писаренко В.И., Непомнящий А.В. Инновационное образование: достижения и перспективы // Высшее образование сегодня. №7, 2007.с.14-19.

6. Рузавин Г.И. Методология научного познания: Учеб. пособие для вузов / Г.И. Рузавин. - М.: ЮНИТИ-ДАНА, 2009. - 287 с.

7. Степин В.С. Теоретическое знание. М., 2000. С.95.

8. Томпсон М. Философия науки / Мел Томпсон. - Пер. с англ. А.Гарькавого. - М.: ФАИР -ПРЕСС, 2003. - 304 с.

9. Юдин Э.Г. Системный подход и принцип деятельности / Э.Г. Юдин. - М.: Наука, 1978. - 392 с.

( Писаренко Вероника Игоревна (vero19671993@gmail.com).

Журнал «Современная наука: актуальные проблемы теории и практики»

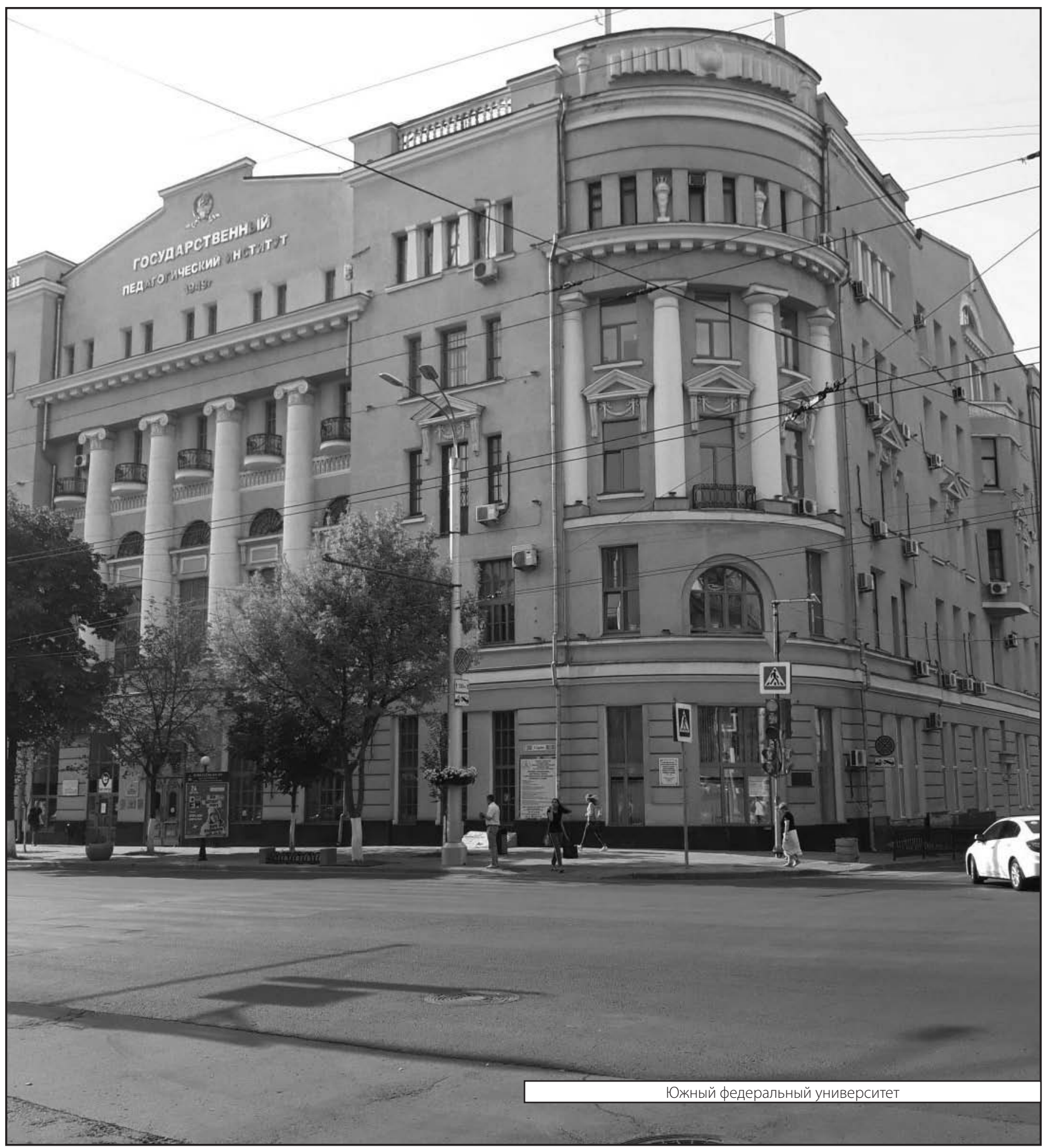

